\title{
Carbohydrate production and transport in cotton cultivars grown under boron
}

\section{deficiency}

\author{
Julio Cesar Bogiani§, Amanda Cristina Esteves Amaro, Ciro Antonio Rosolem*
}

UNESP/FCA - Depto. de Produção e Melhoramento Vegetal, C.P. 237 - 18603-970 - Botucatu, SP - Brazil.

${ }^{*}$ Corresponding author <rosolem@fca.unesp.br>

Edited by: Jussara Borges Regitano/Luís Reynaldo Ferracciú Alleoni

Received August 06, 2012

Accepted June 27, 2013
ABSTRACT: An adequate supply of boron (B) is required for the optimal growth and development of cotton (Gossypium hirsutum L.) plants, but the low phloem mobility of B limits the possibilities of correcting $B$ deficiency. There are indications that different cotton cultivars could have different responses to $B$ deficiency. The differences in responses of cotton cultivars to $B$ regarding photoassimilate production and transport were studied in a greenhouse experiment with nutrient solution. Treatments consisted of three cotton cultivars (FMT 701, DP 604BG and FMX 993) and five concentrations of $B\left(0.0,2.5,5.0,10.0\right.$ and $\left.20.0 \mu \mathrm{mol} \mathrm{L}^{-1}\right)$. Sampling began at the phenological stage B1 (first square) and continued for four weeks. The leaf area and the number of reproductive branches and structures decreased due to $B$ deficiency. A higher level of abortion of reproductive structures was observed under $\mathrm{B}$ deficiency. Boron deficiency increased the internal $\mathrm{CO}_{2}$ concentration but decreased the transpiration rate, stomatal conductance and photosynthesis. Despite the decrease in photosynthesis, nonstructural carbohydrates accumulated in the leaves due to decreased export to bolls in B-deficient plants. The response to B deficiency is similar among cotton cultivars, which shows that the variability for this trait is low even for cultivars with different genetic backgrounds. Keywords: micronutrient, nonstructural carbohydrates, photosynthesis, transpiration

\section{Introduction}

Boron (B) has long been recognized as an essential element (Miwa and Fujiwara, 2010) for plants. Boron participates in cell wall formation (Brown et al., 2002), cell division and elongation (Goldbach et al., 2001; Oliveira et al., 2006), membrane function (Zhao and Oosterhuis, 2003) and carbohydrate metabolism and transport (Zhao and Oosterhuis, 2002; Sheng et al., 2009). Boron deficiency causes a rapid inhibition of plant growth and was believed to have low phloem mobility (Rosolem and Costa, 2000). Although B mobility has been demonstrated in some species (Brown et al., 2002), its role remains controversial (Shaaban, 2010).

Boron is the most commonly deficient micronutrient in cotton (Gossypium hirsutum L.)-producing regions of the world (Ahmad et al., 2009; Rosolem and Bogiani, 2011). Cotton plant responses to B fertilization have been reported previously (Keogh and Maples, 1969), indicating its relevance for cotton crops. Boron deficiency during the stages of flowering and fruiting may reduce cotton boll retention, which results in decreased yields (Miley et al., 1969) due to changes in the source-sink dynamics of the plant (Zhao and Oosterhuis, 2002). The lack of carbohydrates limits boll retention because the B deficiency reduces photoassimilate translocation from leaves to fruits, which increases the number of abortions (Zhao and Oosterhuis, 2003). However, little is known about the changes in photosynthetic activity and nonstructural carbohydrate transport under B-deficient conditions during the flowering stage of cotton.

sPresent address: Embrapa Algodão, R. Osvaldo Cruz, 1143, C.P. 174 58428-09 - Campina Grande, PB - Brasil.
Cotton plants respond positively to B application. However, the range between adequate and phytotoxic rates of application is narrow, and fertilizer application has shown inconsistent results, especially when applied to leaves (Rosolem and Costa, 2000; Oliveira et al., 2006). Although no differences in responses to B have been found among old cotton cultivars (Rosolem et al., 1999), different responses might occur among new cultivars (Fontes et al., 2008), which might have different abilities to use B in carbohydrate transport and storagerelated mechanisms (Ahmad et al., 2009).

In the current study, we evaluated changes in the photosynthetic activity, nonstructural carbohydrate transport and boll retention as affected by B deficiency in cotton cultivars with different genetic backgrounds.

\section{Materials and Methods}

A greenhouse experiment was conducted in Botucatu, state of São Paulo, Brazil $\left(22^{\circ} 52^{\prime}\right.$ S, 48 ${ }^{\circ} 5^{\prime}$ W, 810 $\mathrm{m}$ a.s.l.) using three full-cycle cotton cultivars (Gossypium hirsutum, var. Latifolia) from different breeding programs: FMT 701, FMX 993 and DP604BG. The seeds (with no agrochemical treatment) were germinated in trays containing washed sand. The seedlings were removed from the sand after emergence and transferred to 4-L plastic pots. Two plants were transferred to each pot, which contained a 1:10 dilution of the original nutrient solution (Hoagland and Arnon, 1950). After one week, the solution was replaced with a 1:5 dilution of the original solution, and after another week, the original solution was used until the end of the experiment. Solutions were changed weekly. 
Boron concentrations of $0.0,2.5,5.0,10.0$ and 20.0 $\mu \mathrm{mol} \mathrm{L} \mathrm{L}^{-1}$ were used in all nutrient solutions, including the first (1:10 dilution). The 4-L pots were replaced by 7-L pots upon the fourth nutrient solution change. The nutrient solution was continuously oxygenated throughout the experiment, and was monitored every $2^{\text {nd }}$ day, adding water to maintain the original level. The $\mathrm{pH}$ was measured for each pot and maintained at $5.0 \pm 0.5$ by dripping $0.1 \mathrm{~mol} \mathrm{~L}^{-1} \mathrm{NaOH}$ or $0.1 \mathrm{~mol} \mathrm{~L}^{-1} \mathrm{HCl}$ solutions. Deionized water was used throughout the experiment to prepare the stock and nutrient solutions and wash the materials (all materials were made of plastic).

Four pots per treatment were assigned to each block to allow for weekly destructive samplings, starting one week after stage B1 or first square (Marur and Ruano, 2001), 31 days after plant emergence (DAE) and ending four weeks after stage B1 (59 days after plant emergence). The net $\mathrm{CO}_{2}$ assimilation rate (photosynthesis), intracellular $\mathrm{CO}_{2}$ concentration, stomatal conductance and transpiration rate were measured at the B1 stage and one and four weeks after B1, between 9h00 and $11 \mathrm{~h} 30$, using a portable photosynthesis measuring system (IRGA - LI-6400, LICOR). The measurements were made on the blade of the $4^{\text {th }}$ leaf from the apex, and the leaf with a minimum midrib length of $2.5 \mathrm{~cm}$ was considered to be the first leaf.

The four destructive samplings consisted of collecting the blades of the $4^{\text {th }}$ and $5^{\text {th }}$ leaves in addition to all reproductive structures of each plant to quantify nonstructural carbohydrates (starch, sucrose and fructose + glucose). Samples were dried to constant weight in a convectional oven at $65{ }^{\circ} \mathrm{C}$ and then ground. The total soluble sugar and reducing sugar contents were quantified according to the Somogy-Nelson method (Nelson, 1944; Somogy, 1945). Sucrose content was calculated as the difference between the amount of total soluble sugars and amount of reducing sugars. For starch quantification, the samples were hydrolyzed using $\alpha$-amylase and amyloglucosidase enzymes (AOAC, 1975), followed by the quantification of reducing sugars, from which the starch content was obtained after subtracting the overall level of reducing sugars. Finally, the total leaf area, number of reproductive branches, number of reproductive structures (flower buds, flowers and bolls) and number of aborted reproductive structures (scar counts) were quantified.

The experimental design was of randomized blocks with four replicates in a factorial design with three cultivars and five $B$ rates. The differences among cultivars were compared using the Least Square Difference (LSD) $(p<0.05)$. Polynomial regression analysis was performed to study plant responses to B nutrient concentrations.

\section{Results and Discussion}

Cotton leaf area values decreased in the absence of B (Figure 1A). However, the leaf area values in plants treated with $2.5 \mu \mathrm{mol} \mathrm{L}^{-1} \mathrm{~B}$ were similar to those of plants treated with non-deficient concentrations. The leaf area tended to decrease when the $\mathrm{B}$ concentration in the solution increased from $10 \mu \mathrm{mol} \mathrm{L}{ }^{-1}$ to $20 \mu \mathrm{mol} \mathrm{L}-1$ (Figure 1A), which might indicate toxicity. The first symptoms of toxicity caused by excess B appear on the leaves (Camacho-Cristóbal et al., 2008) because of the low B mobility in cotton plants (Rosolem and Costa, 2000) and leaves are the primary accumulation site (Ahmed, et al., 2008). The maximum number of reproductive branches was found with a B concentration of approximately $12 \mu \mathrm{mol}$ $\mathrm{L}^{-1}$, with no significant variations up to $20 \mu \mathrm{mol} \mathrm{L}-1$.

There was no difference among cultivars regarding the number of reproductive branches (Figure 1B), leaf area or number of reproductive and aborted structures per plant up to four weeks after B1. The number of reproductive structures in plants grown in the absence of $\mathrm{B}$ was approximately zero (Figure $1 \mathrm{C}$ ) due to the high number of abortions (Figure 1D). The number of reproductive structures per plant increased with increasing B concentrations to approximately $11 \mu \mathrm{mol} \mathrm{L^{-1 }}$ in all four samplings, while the number of aborted structures decreased, and no further significant changes were observed when the B concentration was increased up to 20 $\mu \mathrm{mol} \mathrm{L}{ }^{-1}$ (Figures 1C and 1D).

Cotton plants produce a large number of flower buds, and the loss of approximately $50 \%$ of these structures is considered normal (Pereira et al., 2004). However, the abortion of flower buds in B-deficient plants was higher than normal. This increase in abortion occurred because B deficiency impairs the formation of the peduncle vascular system, impairing carbohydrate transport to the ovary (Oliveira et al., 2006) in addition to affecting carbohydrate synthesis (Zhao and Oosterhuis, 2002). Thus, B deficiency, even a temporary deficiency, could impair the setting of reproductive structures depending on nutrient mobility in the cotton plant (Fontes et al., 2008). These results support the report by Zhao and Oosterhuis (2003), who found that the number of flower buds and leaf area of cotton plants decreased three to five weeks after the removal of B from nutrient solutions. The number of flower buds was more sensitive than the leaf area to B deficiency and exhibited a decrease of $85 \%$ in the fifth week after the exclusion of $\mathrm{B}$ from the nutrient solution.

Internal $\mathrm{CO}_{2}$ concentrations at $\mathrm{B} 1$ and one week later were not significantly different. However, at four weeks after B1, plants grown in the absence of B showed increases in internal $\mathrm{CO}_{2}$ concentrations, which decreased up to $11 \mu \mathrm{mol} \mathrm{L}{ }^{-1} \mathrm{~B}$ in solution (Figure $2 \mathrm{~A}$ ).

The transpiration rate at the $\mathrm{B} 1$ stage was not affected by B concentration, although one week later, B had a positive effect at concentrations of up to approximately $10 \mu \mathrm{mol} \mathrm{L}{ }^{-1}$ (Figure $2 \mathrm{~B}$ ). The response in the $4^{\text {th }}$ week after B1 was similar to the response after the $1^{\text {st }}$ week, although the values were lower (Figure 2B). In the absence of $\mathrm{B}$, plant morphological changes occur, especially in the leaves (Oliveira et al., 2006), with a decrease in the number and functioning of stomata 

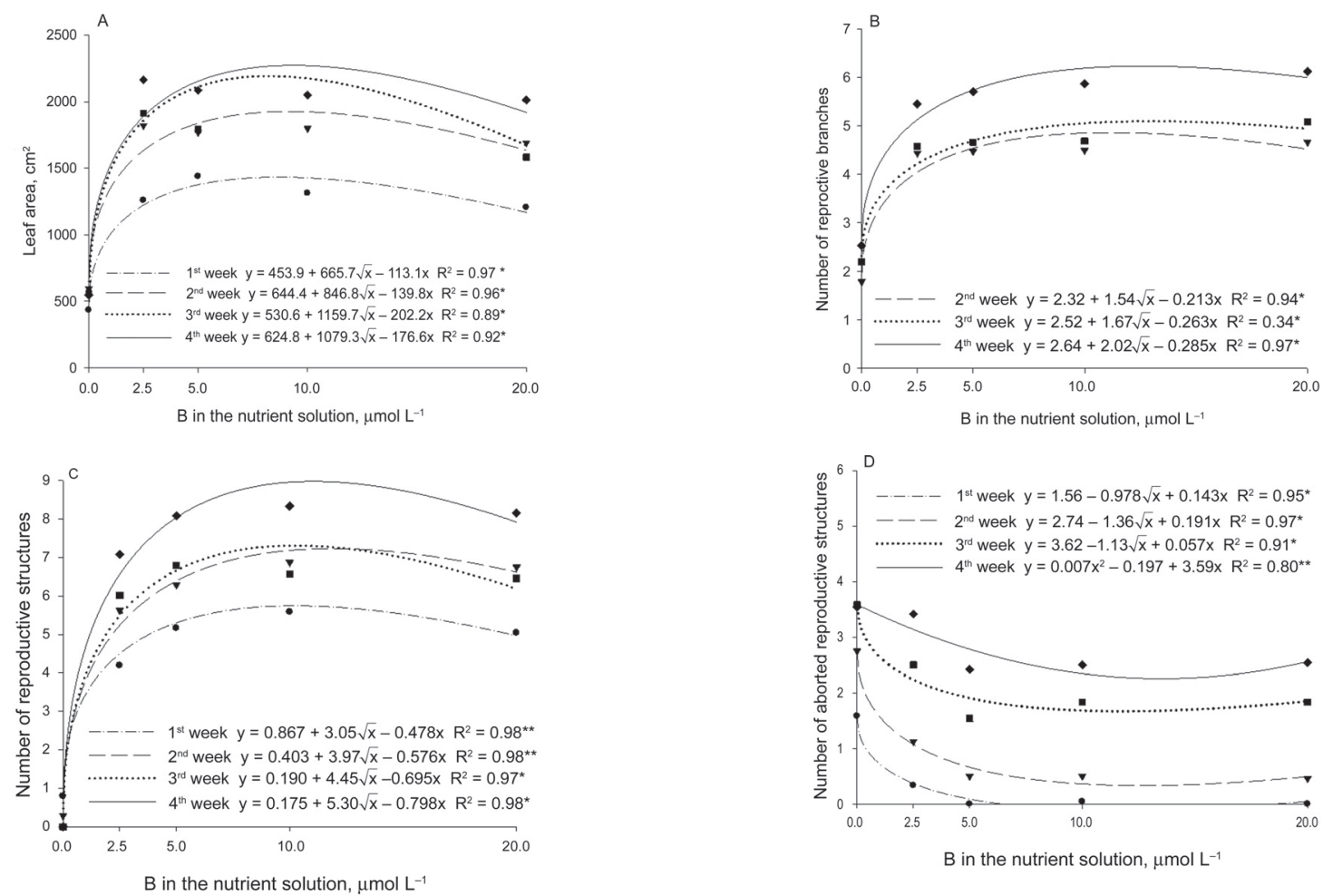

Figure 1 - Leaf area (A), number of reproductive branches (B), number of reproductive structures (C) and number of aborted reproductive structures (D) of cotton cultivars, determined in for weeks after the B1 stage, as affected by rates of boron in the nutrient solution. Averaged over three cultivars. $\bullet, \nabla, \boldsymbol{\nabla}$ and $=1^{\text {st }}, 2^{\text {nd }}, 3^{\text {rd }}$ and $4^{\text {th }}$ week, respectively. ${ }^{*}$ and ${ }^{*}$ significant $(p \leq 0.05$ and 0.01$)$, respectively.
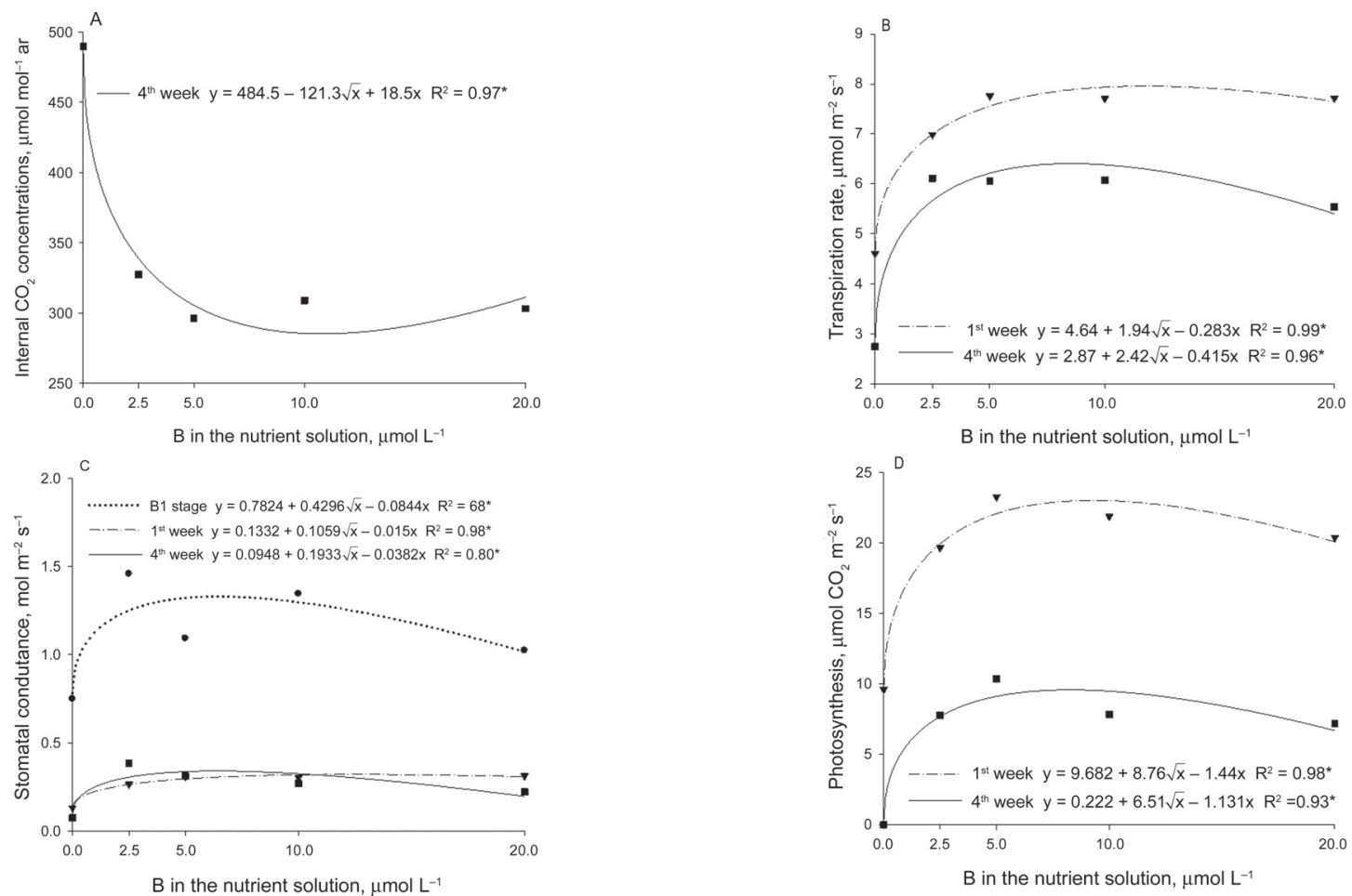

Figure 2 - Internal leaf $\mathrm{CO}_{2}$ concentrations (A), transpiration rate (B), stomatal conductance (C) and photosynthesis (D) of cotton cultivars, determined at the $\mathrm{B} 1$ stage, and in the $1^{\text {st }}$ and $4^{\text {th }}$ weeks after $\mathrm{B} 1$, as affected by rates of boron in the nutrient solution. Averaged over three cultivars. $\bullet, \boldsymbol{\nabla}$ and $\mathbf{~ = ~ B 1 ~ s t a g e , ~} 1^{\text {st }}$ and $4^{\text {th }}$ week, respectively. ${ }^{*}$ and * significant $(p \leq 0.05$ and 0.01$)$, respectively. 
(Rosolem and Leite, 2007), which might impair transpiration (Figure 2B) and $\mathrm{CO}_{2}$ flow in intercellular spaces (Figure 2A).

Stomatal conductance was higher at B1 than at one and four weeks later, although the responses were similar in the three assessments. Cotton plants grown without B in the nutrient solution had lower stomatal conductance, although a concentration of just $2.5 \mu \mathrm{mol}$ $\mathrm{L}^{-1} \mathrm{~B}$ yielded near-maximum values. At $20 \mu \mathrm{mol} \mathrm{L}^{-1} \mathrm{~B}$, the values tended to decrease, possibly due to a toxic effect of B (Figure 2C). The lower stomatal conductance of plants in the absence of B might have resulted from morphological changes in leaves and detrimental changes in stomata (Rosolem and Leite, 2007). Decreased carbohydrate transport, which is observed under B deficiency, causes the accumulation of starch in leaves (Zhao and Oosterhuis, 2002), which might impair physiological activity by increasing the physical restriction inside leaves, resulting in poor stomatal function.

No difference was found between cotton cultivars in terms of internal $\mathrm{CO}_{2}$ concentrations, transpiration rates, stomatal conductance or photosynthesis determined at B1 and one week later. However, four weeks after B1, the DP604BG cultivar showed a lower photosynthetic rate than the other cultivars (Table 1). Therefore, DP604BG is more prone to $\mathrm{B}$ deficiency over longer exposure times. There was no effect of B nutrient concentrations at B1, but differences were observed one week after B1 and persisted for up to four weeks after B1 (Figure 2D).

Photosynthesis was strongly impaired in B-deficient plants; even with a low rate of $\mathrm{B}\left(2.5 \mu \mathrm{mol} \mathrm{L} \mathrm{L}^{-1}\right)$, the rate of photosynthesis was much higher than in the absence of $B$, increasing up to approximately $9 \mu \mathrm{mol} \mathrm{L} \mathrm{L}^{-1}$ $\mathrm{B}$ and remaining approximately constant up to $20 \mu \mathrm{mol}$ $\mathrm{L}^{-1} \mathrm{~B}$ (Figure 2D). Therefore, photosynthesis is impaired in cotton plants with severe B deficiency, though it might be normalized with low nutrient rates. This decrease in photosynthesis might have been due to changes in the transpiration rate and stomatal conductance. Decreased photosynthesis caused by B deficiency has also been found by Han et al. (2009) in citrus plants and Zhao and Oosterhuis (2003) in cotton plants, who reported that the response is due to the decrease in stomatal conductance, as was observed in the current study. Although stomatal conductance was decreased by B deficiency, internal $\mathrm{CO}_{2}$ concentrations were increased by B deficiency. Hence, the B-deficiency-induced decrease in stomatal conductance was not the primary cause for the decreased photosynthesis in cotton, as it has been found in citrus (Han et al., 2008, 2009).

Transpiration rate and stomatal conductance were reported to be decreased in B-deficient cotton plants (Zhao and Oosterhuis, 2003), but unlike the results of the current study, internal $\mathrm{CO}_{2}$ concentrations were also lower. In the $4^{\text {th }}$ week after $\mathrm{B} 1$, the highest internal $\mathrm{CO}_{2}$ concentrations were recorded in plants grown without $B$, which might have been due to adverse effects on stomatal function and decrease in photosynthetic activity. Alternatively, photorespiration might have been high in these plants. A decreased transpiration rate, stomatal conductance and photosynthesis, in addition to increased internal $\mathrm{CO}_{2}$ concentrations, were observed by Sheng et al. (2009) in citrus plants under B deficiency.

Decreased photosynthesis due to B deficiency may be associated with a decrease in carbohydrate transport as a result of the decreased activity of compounds such as uracil, resulting in carbohydrate accumulation (Birnbaum et al., 1977). The decrease in photosynthesis might be due to the disruption of the chloroplast function or inhibition of photosynthetic enzymes (Han et al., 2008) in response to the excessive accumulation of starch and hexoses in leaves. In the current study, the carbohydrate concentrations were highest in plants that were B deficient. The leaf fructose + glucose content was highest in plants that were B deficient. The highest concentrations of these sugars were obtained one and three weeks after $\mathrm{B} 1$ at $\mathrm{B}$ concentrations in solution ranging between 2.5 and $5.0 \mu \mathrm{mol} \mathrm{L}^{-1}$ (Figure 3A). Two and four weeks after $B 1$, the values were highest in plants grown without $B$ and decreased linearly with increasing concentrations of B.

Leaf sucrose content was similar in the four samplings (Figure 2B). Starting from the control treatment with no added $B$, sucrose contents increased to approximately $2.5 \mu \mathrm{mol} \mathrm{L} \mathrm{L}^{-1} \mathrm{~B}$ and then decreased with solution b up to $20 \mu \mathrm{mol} \mathrm{L}^{-1} \mathrm{~B}$ (Figure $2 \mathrm{~B}$ ). The lower content

Table 1 - Mean of the fructose + glucose (Fruct + Glu) and starch content of the leaves and reproductive structures (RE) and photosynthesis, obtained three weeks after B1 stage, in three cotton cultivars for rates of boron in the nutrient solution (Averaged over five B concentrations).

\begin{tabular}{|c|c|c|c|c|c|c|}
\hline \multirow{3}{*}{ Factor } & \multicolumn{2}{|c|}{$1^{\text {st }}$ Week } & \multirow{2}{*}{$\begin{array}{l}3^{\text {rd }} \text { Week } \\
\text { Starch }\end{array}$} & \multirow{2}{*}{$\begin{array}{c}4^{\text {th }} \text { Week } \\
\text { Starch }\end{array}$} & \multirow{2}{*}{$\begin{array}{l}4^{\text {th }} \text { Week } \\
\text { Starch }\end{array}$} & \multirow{3}{*}{$\begin{array}{c}4^{\text {th }} \text { Week } \\
\text { Photosynthesis }\end{array}$} \\
\hline & Starch & Fruct + Glu & & & & \\
\hline & \multicolumn{5}{|c|}{- Leaves $\longrightarrow$} & \\
\hline & & & $-\mathrm{g} \mathrm{kg}^{-1}$ & & & $\mu \mathrm{mol} \mathrm{CO}{ }_{2} \mathrm{~m}^{-2} \mathrm{~s}^{-1}$ \\
\hline FMT 701 & 59.73 & 17.01 & 84.18 & 129.62 & 21.73 & 7.13 \\
\hline DP 604 BG & 59.09 & 13.64 & 82.71 & 129.11 & 20.78 & 3.03 \\
\hline FMX 993 & 60.98 & 17.94 & 85.52 & 134.22 & 21.01 & 6.95 \\
\hline LSD & $0.97^{* *}$ & $2.59^{* *}$ & $1.55^{\text {* * }}$ & $3.86^{*}$ & $0.45^{\star *}$ & $2.98^{*}$ \\
\hline CV(\%) & 2.5 & 15.1 & 2.9 & 4.6 & 3.0 & 14.9 \\
\hline
\end{tabular}

LSD $=$ Least Significant Difference $(p \leq 0.05)$ to compare the means in column; ${ }^{*},{ }^{* *}$ and ${ }^{n s}$, significant $(p \leq 0.05),(p \leq 0.01)$ and non significant, respectively. 
observed under B deficiency might have resulted from a decrease in photosynthesis, similar to the results found in plants supplemented with a low concentration of 2.5 $\mu \mathrm{mol} \mathrm{L}{ }^{-1} \mathrm{~B}$. However, the highest sucrose content was found at $2.5 \mu \mathrm{mol} \mathrm{L}^{-1} \mathrm{~B}$, highlighting the fact that sugar accumulates as a result of the decreased export to drain sites, such as bolls, which showed lower sucrose content at lower B supplementation levels (Figure 4A).
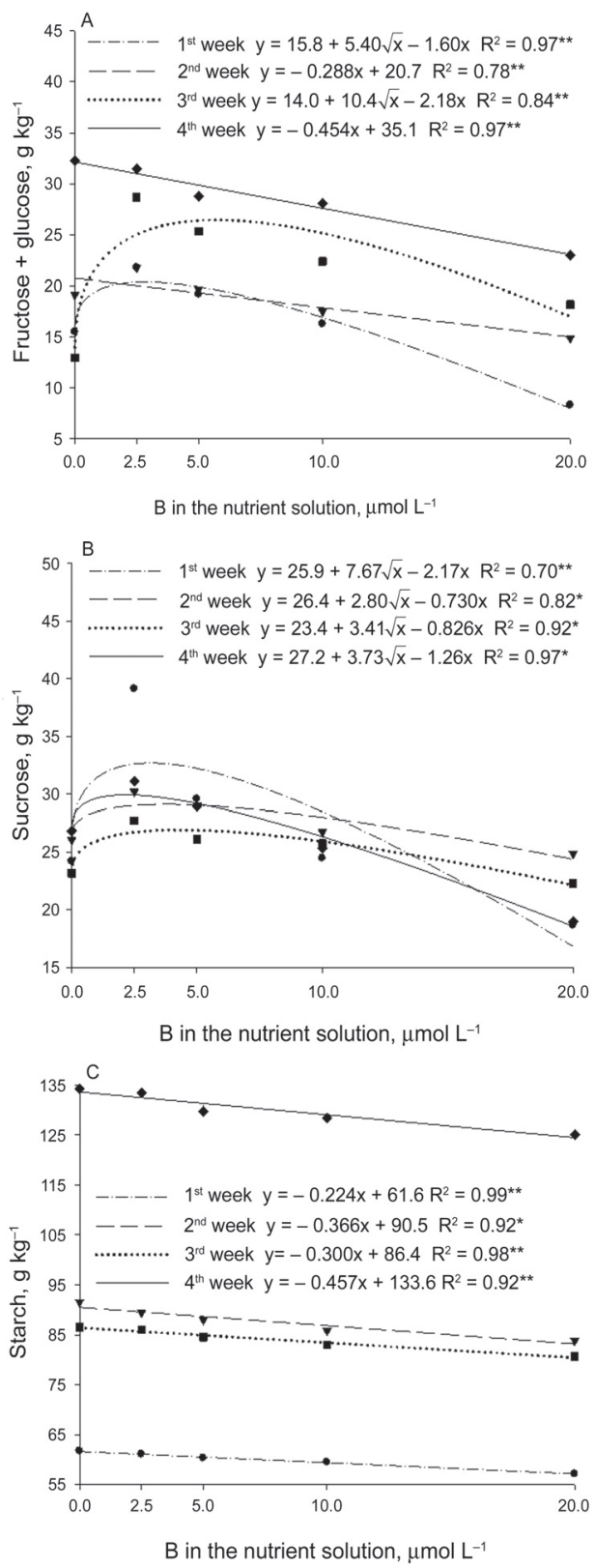

Figure 3 - Contents of fructose + glucose $(A)$, sucrose (B) and starch $(C)$ in cotton leaves, determined in for weeks after the B1 stage, as affected by rates of boron in the nutrient solution. Averaged over three cultivars. $\bullet, \nabla, \bullet$ and $\bullet=1^{\text {st }}, 2^{\text {nd }}, 3^{\text {rd }}$ and $4^{\text {th }}$ week, respectively. ${ }^{*}$ and ${ }^{* *}$ significant $(p \leq 0.05$ and 0.01$)$, respectively.
Leaf starch content decreased linearly with increasing B concentrations (Figure 3C). The leaf starch content increased from the first to the $4^{\text {th }}$ week, and the rate of decrease in content with increasing $\mathrm{B}$ concentrations as indicated by the regression equation slope in the fourth week is approximately double of that of the rate in the first week (Figure 3C). Han et al. (2008) reported an increase in leaf nonstructural carbohydrate content as a result of lower B availability, high starch content in B-deficient leaves might be due to the low carbohydrate demand for plant growth, which is inhibited under B deficiency, as reported in several studies on cotton plants (Rosolem and Costa, 2000; Zhao and Oosterhuis, 2003).

These results are supported by Zhao and Oosterhuis (2002), who found increased leaf accumulation of glucose, fructose, sucrose and starch five weeks after inducing B deficiency in cotton, with the greatest accumulation of starch occurring in the third week. Five weeks after inducing B deficiency, the levels of these nonstructural carbohydrates in the flower buds were ap-
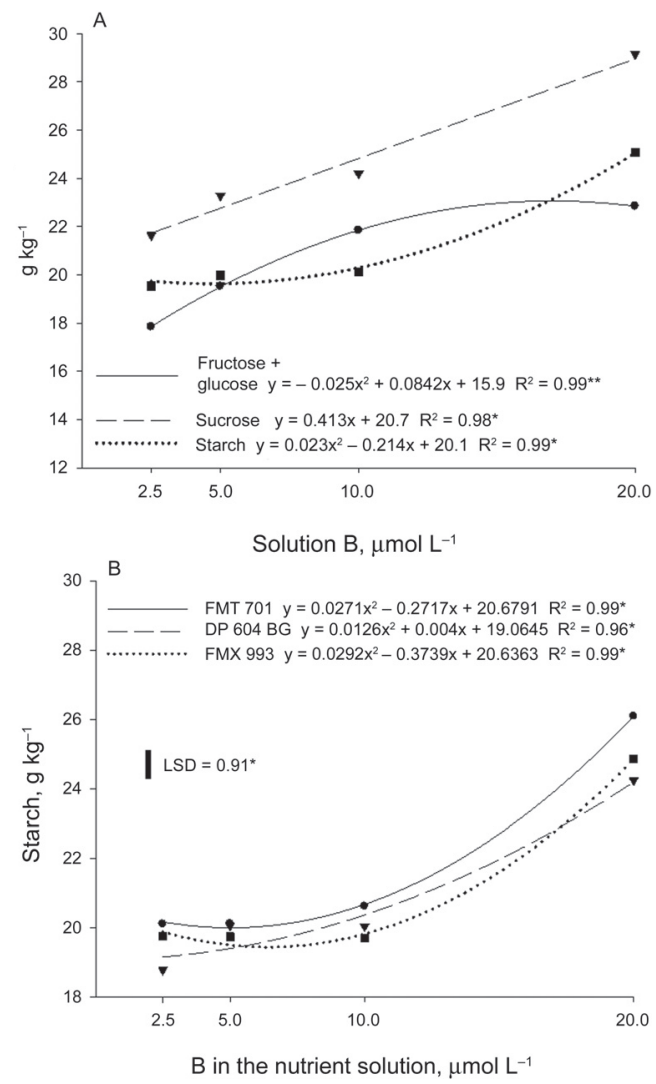

Figure 4 - Fructose + glucose, sucrose and starch content $(A)$ in the reproductive structures (averaged over three cotton cultivars), $\bullet$, $\boldsymbol{\nabla}$ and $\mathbf{m}=$ Fructose + glucose, sucrose and starch, respectively; and starch content (B) in the reproductive structures in three cotton cultivars, obtained for weeks after B1, as affected by rates of boron in the nutrient solution. $\bullet, \nabla$ and $\boldsymbol{\bullet}=$ FMT701, DP604BG e FMX993, respectively. * and ${ }^{* *}$ significant ( $p \leq 0.05$ and 0.01), respectively. LSD $=$ Least Significant Difference $(p \leq 0.05)$. 
proximately half of those observed in plant structures with normal B availability. A similar response was observed in the current study. The lowest levels of all carbohydrates were found in the reproductive structures of plants grown with $2.5 \mu \mathrm{mol} \mathrm{L}{ }^{-1} \mathrm{~B}$ (Figure 4A).

When $\mathrm{B}$ concentration in solution was increased to $10 \mu \mathrm{mol} \mathrm{L} \mathrm{L}^{-1}$, there was a significant increase in the fructose + glucose content, but the increases observed with increasing $B$ solution concentrations up to $20 \mu \mathrm{mol} \mathrm{L} \mathrm{L}^{-1}$ were small (Figure 4A). Conversely, the starch content in the reproductive structures was nearly unchanged with B solution concentrations of up to $10 \mu \mathrm{mol} \mathrm{L}{ }^{-1}$, and the starch content values strongly increased with increases in B concentration from 10 $\mu \mathrm{mol} \mathrm{L}-1$ to $20 \mu \mathrm{mol} \mathrm{L}-1$.

Sucrose content increased linearly with B concentrations (Figure 4A). One hypothesis is that carbohydrate export from the leaves to the bolls is impaired by $B$ deficiency (Figure 3B) because the sucrose formed in the photosynthetic organs is the main sugar transported through the phloem to consumption sites. This interpretation is confirmed by the abortion of all structures that were emitted in plants grown in the absence of B. Carbohydrate transport to the reproductive structures in B-deficient plants might also be impaired by the disruption of the vascular system in the peduncle region, which leads to the abortion of flower buds (Oliveira et al., 2006). Thus, B plays a key role in the formation and fixation of bolls. Under B deficiency conditions, a yield decrease is likely to occur due to the increase in the abortion of reproductive structures, fewer bolls per plant and probable formation of smaller and lighter bolls.

There was generally no difference in the fructose + glucose and sucrose content among cultivars despite the differences in leaf fructose + glucose content observed one week after B1, with a lower value found in DP604BG (Table 1). However, with the exception of the second week after B1, during which all cultivars showed similar leaf starch levels, FMX 993 had higher leaf starch content, indicating greater accumulation of starch in its leaves (Table 1). No significant correlation was found between the cultivar and $\mathrm{B}$ concentration in the nutrient solution.

The fructose + glucose and sucrose levels in reproductive structures did not differ among cultivars, but DP604BG showed lower content than the other cultivars in the fourth week after B1 (Table 1). There was an interaction between the cultivars and $\mathrm{B}$ concentrations in terms of starch content in the reproductive structures: at $2.5 \mu \mathrm{mol} \mathrm{L}^{-1} \mathrm{~B}, \mathrm{DP} 604 \mathrm{BG}$ had lower values than the other cultivars, indicating that this cultivar might have a disadvantage in carbohydrate transport to bolls under $\mathrm{B}$ deficiency conditions. There were no differences between cultivars from 5 to $10 \mu \mathrm{mol} \mathrm{L}{ }^{-1} \mathrm{~B}$, but FMT 701 showed higher content than the other cultivars at 20 $\mu \mathrm{mol} \mathrm{L}{ }^{-1} \mathrm{~B}$ (Figure $4 \mathrm{~B}$ ). These differences did not change the number of plant reproductive structures, which were similar for all cultivars.
In summary, B deficiency during the reproductive phase of cotton directly affects productivity by decreasing the production of carbohydrates and their export from leaf to boll, what results in decreased boll retention. The B demand for cotton boll retention is greater than for plant development in general. Despite differences in the photosynthetic rate and partitioning of starch, cotton varieties from diverse genetic backgrounds do not differ in their responses to B in terms of biological productivity and retention of reproductive structures.

\section{References}

Ahmed, N.; Abid, M.; Ahmad, F. 2008. Boron toxicity in irrigated cotton (Gossypium hirsutum L.). Pakistan Journal of Botany 40: 2443-2452.

Ahmad, S.; Akhtar, L.H.; Iqbal, N.; Nasim, M. 2009. Cotton (Gossypium hirsutum L.) varieties responded differently to foliar applied boron in terms of quality and yield. Soil and Environment 28: 88-92.

Association of Official Analytical Chemists [AOAC]. 1975. Official Methods of Analysis. 12ed. AOAC, Washington, DC, USA.

Birnbaum, E.H.; Dugger, W.M.; Beasley, C.A. 1977. Interaction of boron with components of nucleic acid metabolism in cotton ovules culture in vitro. Plant Physiology 59: 10341038.

Brown, P.H.; Bellalaui, N.; Winner, M.A.; Bassil, E.S.; Ruiz, J.; Hu, H.; Pfeffer, H.; Dannel, F.; Römheld, V. 2002. Boron in plant biology. Plant Biology 4: 205-223.

Camacho-Cristóbal, J.J.; Rexach, J.; González-Fontes, A. 2008. Boron in plants: deficiency and toxicity. Journal of Integrative Plant Biology 50: 1247-1255.

Fontes, R.L.F.; Medeiros, J.F.; Neves, J.C.L.; Carvalho, O.S.; Medeiros, J.C. 2008. Growth of Brazilian cotton cultivars in response to soil applied boron. Journal of Plant Nutrition 31: 902-918.

Goldbach, H.E.; Yu, Q.; Wingender, R.; Schulz, M.; Wimmer, M; Findeklee, P.; Baluska, F. 2001. Rapid response reactions of roots to boron deprivation. Journal of Plant Nutrition and Soil Science 164: 173-181.

Han, S.; Chen, L.S.; Jiang, H.X.; Smith, B.R.; Yang, L.T.; Xie, C.Y. 2008. Boron deficiency decreases growth and photosynthesis, and increases starch and hexoses in leaves of citrus seedlings. Journal of Plant Physiology 165: 1331-1341.

Han, S.; Tang, N.; Jiang, H.X.; Yang, L.T.; Li, Y.; Chen, L.S. 2009. $\mathrm{CO}_{2}$ assimilation, photosystem. II. Photochemistry, carbohydrate metabolism and antioxidant system of citrus leaves in response to boron stress. Plant Science 76: 143-153.

Hoagland, D.R.; Arnon, I. 1950. The Water Culture Method for Growing Plants without Soil. University of California, Sacramento, CA, USA. (Circular of California Agricultural Experiment Station, 347).

Keogh, J.L.; Maples, R. 1969. Boron for Cotton and Soybeans on Loessial Plains Soils. Arkansas Agricultural Experiment Station, Fayetteville, AR, USA. (Bulletin, 740).

Miley, W.N.; Hardy, G.W.; Sturgis, M.B.; Sedberry Jr., F.E. 1969. Influence of boron, nitrogen and potassium on yield, nutrient uptake and abnormalities of cotton. Agronomy Journal 61: 9-13. 
Miwa, K., Fujiwara, T. 2010. Boron transport in plants: coordinated regulation of transporters. Annals of Botany 105: 1103-1108.

Nelson, N. 1944. A photometric adaptation of the Somogy method for the determination of glucose. Journal of Biological Chemistry 153: 375-378.

Oliveira, R.H.; Milanez, C.R.D.; Dallaqua, M.A.M.; Rosolem, C.A. 2006. Boron deficiency inhibits petiole and peduncle cell development and reduces growth of cotton. Journal of Plant Nutrition 29: 2035-2048.

Rosolem, C.A.; Esteves, J.A.F.; Ferelli, L. 1999. Response of cotton cultivars to boron in nutrient solution. Scientia Agricola 56: 705-711 (in Portuguese, with abstract in English).

Rosolem, C.A.; Bogiani, J.C. 2011. Physiology of boron stress in cotton. p. 113-124. In: Oosterhuis, D.M., ed. Stress physiology in cotton. The Cotton Foundation, Cordova, TN, USA.

Rosolem, C.A.; Costa, A. 2000. Cotton growth and boron distribution in the plants as affected by a temporary deficiency of boron. Journal of Plant Nutrition 23: 815-825.
Rosolem, C.A.; Leite, V.M. 2007. Coffee leaf and stem anatomy under boron deficiency. Revista Brasileira de Ciência do Solo 31: 477-483.

Shaaban, M.M. 2010. Role of boron in plant nutrition and human health. American Journal of Plant Physiology 5: 224-240.

Sheng, O.; Song, S.; Peng, S.; Deng, X. 2009. The effects of low boron on growth, gas exchange, boron concentration and distribution of "Newhall" navel orange (Citrus sinensis Osb.) plants grafted on two rootstocks. Scientia Horticulturae 121: 278-283.

Somogy, M. 1945. Determination of blood sugar. Journal of Biological Chemistry 160: 69-73.

Zhao, D.; Oosterhuis, D.M. 2002. Cotton carbon exchange, nonstructural carbohydrates, and boron distribution in tissues during development of boron deficiency. Field Crops Research 78: 75-87.

Zhao, D.; Oosterhuis, D.M. 2003. Cotton growth and physiological responses to boron deficiency. Journal of Plant Nutrition 26: 855-867. 